\title{
Products in environmental management systems: drivers, barriers and experiences
}

\author{
Jonas Ammenberg and Erik Sundin
}

\section{Linköping University Post Print}

\section{Tweet}

N.B.: When citing this work, cite the original article.

Original Publication:

Jonas Ammenberg and Erik Sundin, Products in environmental management systems: drivers, barriers and experiences, 2005, Journal of Cleaner Production, (13), 4, 405-415.

http://dx.doi.org/10.1016/j.jclepro.2003.12.005

Copyright: Elsevier

http://www.elsevier.com/

Postprint available at: Linköping University Electronic Press

http://urn.kb.se/resolve?urn=urn:nbn:se:liu:diva-13541 


\section{Products in Environmental Management Systems: Drivers, Barriers and Experiences}

Jonas Ammenberg* (a) and Erik Sundin (b)

(a) Environmental Technique and Management

Department of Mechanical Engineering

Linköping University

S-581 83 Linköping, Sweden

(b) Production Systems

Department of Mechanical Engineering

Linköping University

S-581 83 Linköping, Sweden

\section{Abstract}

Do standardised environmental management systems (EMS) lead to improved environmental performance? This depends on to what extent these systems lead to changes in important flows of material and energy, which for manufacturing companies, in turn, mean that the product development process is important. Consequently, it appears vital to investigate the connection between EMS and "Design for the Environment" (DFE), i.e. the connection between these management systems and concepts that deal with environmental issues in product development.

This paper presents product-oriented environmental management systems (POEMS), including characteristics of existing models, experiences from projects where these models have been tested and experiences concerning the product connection in 'normal' EMS. It includes a discussion of important factors influencing to what extent DFE activities are integrated into EMS and/or the outcome of such integration.

There are many motives for integrating the two concepts. Firstly, DFE-thinking might enrich EMS by contributing with a life-cycle perspective. If EMS encompassed products' life cycles to a greater extent, they would be a better complement to the often facility-oriented legal requirements and authority control. Secondly, EMS might remove the pilot project character of DFE activities and lead to continuous improvement. Thirdly, integration could lead to successful co-operation, both internally and externally. However, existing studies show that there is a mixed picture concerning to what extent 'normal' EMS encompass products today.

Keywords: Product Oriented Environmental Management Systems, POEMS, Design for the Environment, DFE, Ecodesign, ISO 14001, EMAS.

\footnotetext{
* Corresponding author: E-mail: jonam@ikp.liu.se, Tel: +46 1328 12 37, Fax: +46 13281101.
} 


\section{Introduction}

Today, more than 57,000 companies are using standardised environmental management systems $^{1}$ (EMS) in the world ${ }^{2}$ [3] and this number is expected to continue to grow steadily [4]. Therefore, it is interesting to study if and how standardised EMS affect companies' environmental impact. It is the authors' experience that many companies, authorities and individuals regard a certification in accordance with ISO 14001 as a guarantee for good environmental performance. However, it appears to be too early to draw any general conclusions on the connection between standardised EMS and environmental performance, because there are research findings pointing in both positive and negative directions [5].

Since environmental impacts are intimately connected to flows of materials and energy, and the most important flows, at least for manufacturing companies, are closely linked to products [cf. 6, 7] it seems urgent for management systems to encompass products and product development. Consequently, it is of great interest to illuminate how standardised EMS are related to Design for the Environment ${ }^{3}$ (DFE), i.e. to what extent they encompass the products and product development procedures. To deal with these issues, this paper aims to elucidate the following topics:

- What are the incentives to strengthen the connection between EMS and DFE?

- How can DFE activities be incorporated into standardised EMS?

- How common is it that EMS encompass DFE activities?

- What are the experiences from projects where EMS and DFE activities have been integrated?

- Which important factors influence to what extent EMS and DFE activities are integrated and/or the outcome of such integration?

\section{Products in Environmental Management Systems}

Historically, DFE and EMS have, to a large extent, existed in separate spheres [9]. Reading through ISO 14001 it is clear that product development is not emphasised and that most product-related requirements leave substantial room for interpretation [10]. Therefore it is uncertain to what extent normal EMS encompass and influence the environmental load of products. However, in 1995 the Dutch government introduced a product policy with the intention of changing the behaviour of producers [11, as referred to in 12]. This was to be accomplished through the implementation of product-oriented environmental management systems (POEMS). A POEMS is an EMS with a special focus on the continuous improvement of a product's eco-efficiency (ecological and economic) along the life cycle, through the systematic integration of ecodesign in the company's strategies and practices [13]. This Dutch product policy can be seen as a starting point for the wide use of POEMS. Since such management systems are constructed to handle product issues they serve well as a basis for this paper. We distinguish between 'normal' EMS and POEMS, where the first category includes standardised EMS that may encompass products and the second comprises systems

\footnotetext{
${ }^{1}$ i.e. EMS fulfilling the requirements of ISO 14001 [1] and/or the European Union's regulation EcoManagement and Audit Scheme (EMAS), [2].

2 July 2003.

${ }^{3}$ DFE is defined as: “A practice by which environmental considerations are integrated into product and process engineering procedures. Design for Environment (ecodesign) practices are meant to develop environmentally compatible products and processes while maintaining product, price, performance and quality standards” [8, a definition of Ecodesign].
} 
prepared to specially deal with product-related issues. POEMS may be based on an existing normal EMS, but this is not necessary.

\section{Motives to integrate EMS and DFE concepts}

Sinding [14] argues that traditional environmental policy in many respects encourages an internal, firm-centred focus. He wants companies to apply an approach that transcends the boundaries of the individual firm and to actively engage in inter-organisational environmental management. However, it is clear that products and product development are not within the main focus of ISO 14001 and its application [10, 15]. According to Cramer [16] the primary focus of EMS has initially been on procedures to reduce emissions through process improvements. Moreover, Klinkers et al. [17] are of the opinion that EMS often are directed at site levels, which is supported by others $[9,10,12,18]$. This indicates that EMS often lack a life-cycle perspective and are not primarily focused on products. Ries et al. [18] state that, in spite of the inclusion of 'activities, products and services' in vital parts of the ISO 14001 standard [1], many companies have a very narrow perception of their environmental impacts, which is mostly limited to site-specific activities. All these facts show that there is an obvious risk that EMS are not directed at the most important environmental aspects. Environmental managers that Ries et al. [18] have interviewed stated that companies generally have very limited knowledge regarding the environmental aspects of their products. Further studies by Ammenberg and Hjelm [15] and Hjelm et al. [19] show that there are certified EMS without a strong link to products.

From an environmental standpoint, it is important to regard the whole life cycle of a product. In this respect, "DFE thinking” or "life-cycle thinking” could function as an important complement to EMS by contributing a better understanding of which flows of materials and energy are most important [cf. 20], which would reduce the risk of suboptimisations. A substantial idea behind POEMS is that they should improve the co-operation in the entire supply chain (from material extraction to end-of-life treatment). POEMS are supposed to lead to concerted environmental action among the actors within a product's life cycle, which is to be commercially beneficial [12]. This is in line with the thoughts of Sinding [14], whose inter-organisational environmental management is intended to lead to learning about environmental impacts throughout the supply chain and to interaction with other firms in the supply chain to reduce these impacts. A change in focus of EMS, from site-specific to encompass the life cycle of products, is also motivated from an environmental policy perspective. If EMS to a greater extent encompassed products' life cycles, they would be a better complement to the often facility-oriented legal requirements and authority control.

Many researchers have developed tools for integration of environmental aspects into the product development process ${ }^{4}$. Although there are quite a lot of DFE-tools developed by academia and industry, few have made a significant breakthrough so far. According to McAloone [22] not much effort has been made on how to integrate these methods into the design process [cf. 23]. Lenox and Ehrenfeld [24] state that many tool developers fail to consider the organisational context in which tools are to be imbedded. In addition, many DFE initiatives have a pilot project character $[20,25]$. This is seen as a problem, since companies tend to return to 'business as usual' after completing such DFE projects, i.e. the long-lasting strategic and organisational changes and the accompanying product improvements are missing. Brezet and Rocha [25] state: "It is recognised that eco-design activities will be limited if they are not integrated into strategic management and the daily operations of

\footnotetext{
${ }^{4}$ For a good description and characterisation of various DFE (ecodesign) tools, see e.g. [21].
} 
companies in a dynamic process of continuous environmental performance improvements" [cf. 26]. Standardised EMS have the potential to remove this barrier to DFE implementation by establishing an organisational structure where procedures for the inclusion of environmental criteria are facilitated and such procedures are made permanent.

It is the authors' experience that an EMS, generally, is designed and administered by environmental managers. To what extent such systems reach out to different groups of employees varies greatly amongst companies. Both for EMS and DFE activities, it is crucial to motivate and involve the right persons within the firm. One important question concerns to what extent managers and staff responsible for product development co-operate. Charter and Belmane [20] state that DFE activities tend to be managed by environmental management functions rather than being integrated into mainstream product development. They also conclude that POEMS require higher co-operation amongst different business functions compared to conventional product development. In a study by Grüner et al. [27], it was found that cross-functional groups, for the integration of environmental aspects into product development, were only implemented in a few of the investigated companies, and even in those companies the groups met too seldom to have a real influence.

\section{Models for POEMS}

Every firm has its individual needs, capabilities, etc. Consequently, it is not possible to develop a POEMS model that expressly fits every company. On the contrary, a model for a wide application must address the integration of EMS and DFE on a general level, allowing flexibility. In this section, some general characteristics of such existing POEMS models are presented and discussed.

Many of the POEMS models presented in the literature are based on the Deming cycle ${ }^{5}$, i.e. the same management cycle as is the basis for ISO 14001 and ISO 9001 ('Plan-Do-Check-Act cycle; PDCA-cycle'). The basic idea behind this approach is to facilitate the establishment of POEMS that are compatible with many companies' existing or future management systems or practices, which seems wise. For example, Brezet et al. [29] conclude that companies having a quality management system have major advantages in taking a structured approach to product-oriented environmental management ${ }^{6}$ [cf. 30]. According to Charter and Belmane [20], an existing normal EMS can easily be extended to a POEMS.

A cursory study of different POEMS models, e.g. models presented by Cramer and Alders [31], Karlsson [9], Klinkers et al. [17], Rocha and Brezet [13], and Rocha and Silvester [32], shows that they are quite similar on a general level. However, different terminology is used and the categorisation of what belongs in the different steps of Plan, Do, Check and Act varies. On an overall level, and based on the references cited above and the authors' own experience, the following general steps of most of the product-related parts of a POEMS model can be stated as follows ${ }^{7}$, see Figure 1 . The described process is mainly focused on the first implementation of a POEMS, which could be carried out by companies with or without an existing EMS or other management systems.

\footnotetext{
${ }^{5}$ See [28] for more information on the "Deming cycle".

${ }^{6}$ This concerns a project where the PDCA-cycle has been used for the POEMS model.

7 The traditional EMS activities are not within the scope of this paper. They are carried out parallel to the more product-related activities listed.
} 


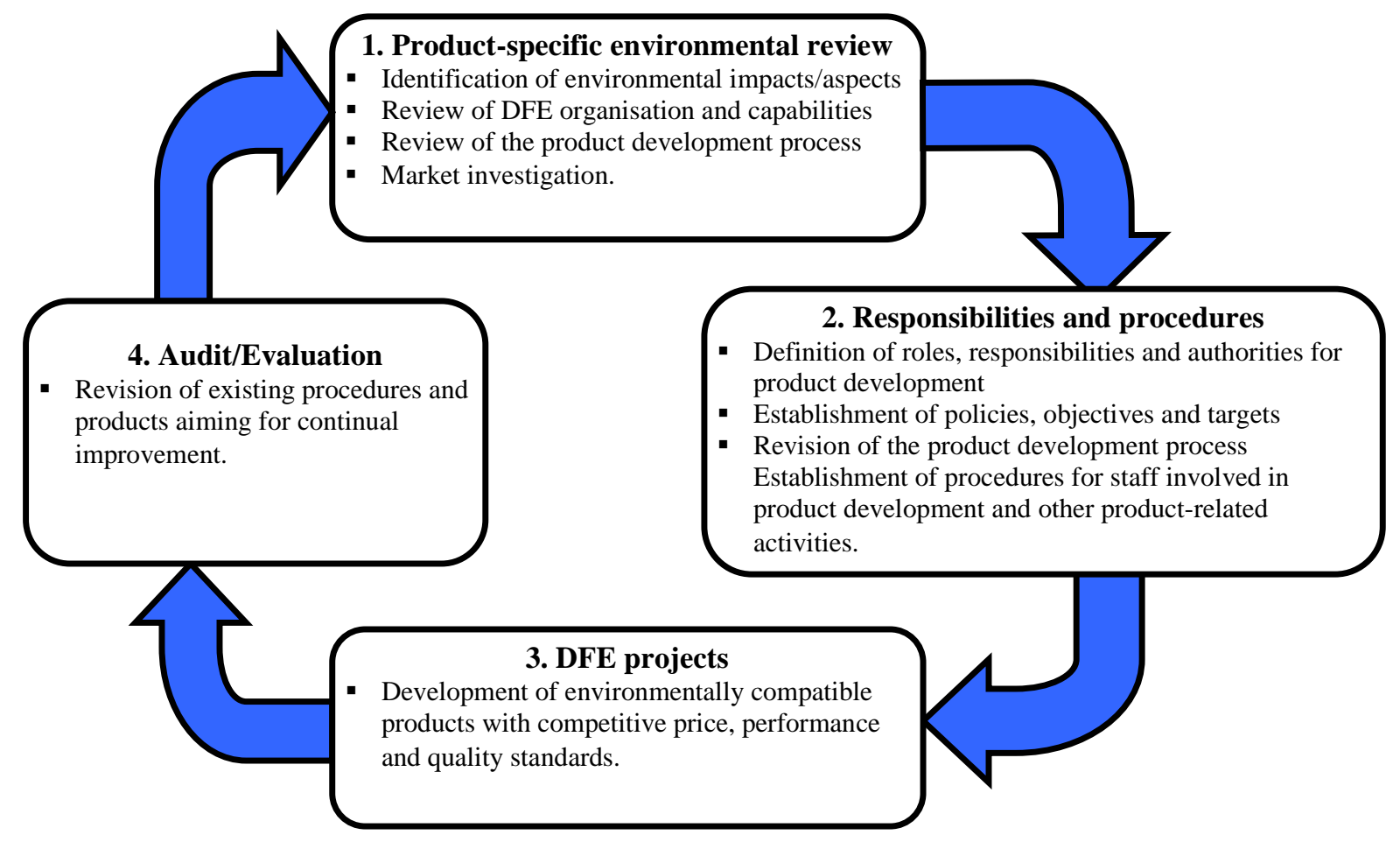

Figure 1. General steps of a POEMS model.

Firstly, a review of the product portfolio from a life-cycle perspective is carried out. This is supposed to contribute with knowledge about the products' environmental impact, which means that product-related environmental aspects are illuminated and it is determined which of these aspects are significant. Since this review to large extent should involve the products' life cycles it encompasses important actors in the supply chain, contradictory to many reviews within normal EMS [10]. Parallel to this process, a review of organisational aspects of DFE relevance should be conducted. This review will bring knowledge about the capabilities and weaknesses of the organisation and will also include an investigation and clarification of the product development process. It is advantageous if these two review phases yield information on the existing and future market (e.g. information on future customer needs).

Secondly, responsibilities and resources should be allocated and environmentally related procedures written for the product development process. It is recommended that environmental concerns should be incorporated from the beginning of the design process and handled as any other design parameter [9]. Furthermore, as much work as possible should be carried out before the product development process, since the possibilities to make changes in product design decrease with time, as the cost for these changes increases with time [33]. It is important to have support from top management and to ensure that corporate visions, strategies and policies are in line with the intentions of the environmentally adapted product development process. Based on the initial reviews and relevant policies, product-related environmental objectives and targets should be established.

Thirdly, DFE projects should then be performed at the operational level. These DFE activities should follow the procedures established in the second step and as much as possible use the information gained in the first step. If new products are designed that are clearly different from existing ones, new investigations will be needed. It should be observed that POEMS might include several parallel Deming cycles, as one concerns the overall EMS and others are 
focused on single-product projects. This implies that the third step may include several more or less separate PDCA-cycles. Naturally, it is advantageous if the environmental concerns do not negatively affect the time for market introduction, price and quality. Cornerstones are a motivated and competent staff, projects involving the right persons [cf. 34], available information on environmental impact and the market situation, well-known usable tools and methods, and sufficient technical capabilities.

Fourthly, the POEMS activities must be evaluated/audited, which is supposed to lead to a good base for reaching continual improvement. Based on these audit procedures, measures should be taken to continually improve the product-related environmental performance.

\section{Experiences concerning POEMS and products in normal EMS}

Studies investigating the environmental and commercial effectiveness of standardised EMS are scarce [5]. There are only a few studies on to what extent products are encompassed by such normal EMS. Furthermore, there is a lack of knowledge concerning the effectiveness of POEMS. Hence, it is far too early to draw any generally applicable, statistically significant, conclusions on to what extent EMS and DFE principles are integrated and how such integration affects environmental performance and business. However, it is possible to use existing studies, both of normal EMS and of POEMS, to draw up a picture of to what extent EMS include product issues and of the potential benefits and drawbacks of POEMS. It is noteworthy that many of the studies of POEMS that this paper is based on involved action research. This means that the researchers have been actively involved in the process they have studied. Nevertheless, this is a methodological aspect that has not been given much attention in their reports and papers. This means that it is even more difficult to comprehend to what degree POEMS projects are dependent on and influenced by participating researchers and consultants. In the following paragraphs, the experiences from a recent study conducted by the authors and the most important results found in the literature are summarised.

\section{Experiences with POEMS}

Rocha and Silvester [32] studied 10 companies that have participated in a Dutch programme, which was intended to stimulate the adoption of POEMS. These researchers defined 34 different POEMS activities and studied their adoption. The results clearly show that the POEMS projects evaluated have led to a significant number of POEMS activities. Only 6\% of the activities were conducted before the beginning of the project. However, the results also show that 122 out of 340 activities were discontinued, i.e. 36\%. Two of the ten companies did not continue any of the activities that were introduced by the project. Consequently, an interesting finding is that many activities arose due to the project, though it is somewhat unclear as to what extent the pilot project character of DFE activities has been eliminated.

Fortunately, from an environmental point of view, 31\% of the total number of activities were commenced after the project and were judged as continuous activities, of which many occurred at the operational level.

Brezet et al. [29] have investigated the experiences of 40 Dutch companies that participated in a subsidy scheme, where POEMS were implemented. They conclude that most companies felt positive about the outcome in terms of gained knowledge and established environmental goals. However, the companies seemed to have problems maintaining contacts with the actors in the production chain. An important reason for this was that many firms regarded themselves as small in the chain, i.e. with limited possibilities to influence. 
Van Berkel et al. [12] point out collection and processing of environmental product information as a key bottleneck of POEMS, in particular for SMEs. In addition, they believe that POEMS efforts will benefit significantly from simplified and sector-specific life cycle assessment tools.

\section{Experiences concerning normal EMS}

The authors recently conducted a study to investigate how external environmental auditors interpret and apply product-related requirements of ISO 14001 at Swedish manufacturing companies in Sweden [10]. The results indicated that the link between normal EMS and products is rather weak. Product issues are seldom regarded as significant environmental aspects and are therefore not within the main scope of many EMS, which mainly focus on sites. However, all of the interviewed auditors required that some kind of environmental considerations be incorporated into the process of product development, but these considerations are to large extent site-oriented; how they are prioritised in relation to other factors such as economy and business appears to be up to the companies.

Karlsson [9] interviewed 59 environmental managers, or corresponding staff, from the manufacturing and furniture industry in Sweden. These firms ranged from only a few employees to several hundred. Karlsson is of the opinion that many organisations routinely include environmental issues in their product development and the survey showed that product development to a large extent was included in EMS based on ISO 14001, and that the introduction of ISO 14001 had often led to an increase of DFE activities. He says that "many industries that have not considered environmental issues in product development start to do that when they implement ISO 14001. Furthermore, it has been found that a DFE management program can enhance an existing environmental management system through the broadening of its scope.” This last result appears to be in line with the finding of van Hemel [35, as referred to in 13], who concludes that EMS can be a stepping stone towards ecodesign and vice versa.

Ries et al. [18] seem to believe in the potential of POEMS, but indicate that Swiss companies, at least a few years ago, had not progressed very far. They state: "Product development is becoming a more and more important part of the environmental management systems of companies. Integrating environmental aspects in early planning stages promises to both improve the environmental performance and customer benefit of products. However, most companies have not reached that far yet. The main difficulty is seen in the poorly developed interface between environmental management functions and departments for research and development.”

Grüner et al. [27] studied 34 German companies using normal EMS. One important result of the study was that no or only a very weak link between EMS and product development was observed. In this respect, EMAS seemed to result in a better integration of product issues than ISO 14001.

Hjelm et al. [19], who have studied a few smaller Swedish companies, conclude that the study clearly showed that it is not, in practice, an absolute requirement that products are included in a standardised EMS. They argue that the number of DFE activities would increase if the external environmental auditors required environmental procedures in the product development process before approving an EMS [cf. 36]. This argumentation is in line with recommendations of Karlsson [9], who would like to see more DFE competent consultants 
and auditors. For this to be realised, adjustments in the standard ISO 14001 and its application might be needed.

\section{Conclusions on experiences}

Results on POEMS are scarce. Therefore general conclusions on the effects of POEMS cannot be drawn. Based on case studies, it is known that POEMS projects driven and supported by, for example, consultants may be fruitful. However, it is not known to what extent companies 'spontaneously', i.e. without participation in a particular project, implement POEMS.

Studies of normal EMS show that researchers have different opinions concerning to what extent EMS encompass and affect product issues. Their opinions appear to range from very positive to a bit hesitant. Some results bear witness to the fact that EMS and DFE activities are integrated in reality, while other findings indicate that the link between EMS and DFE is weak.

\section{Important factors influencing the use and outcome of POEMS}

There is no simple answer that can explain this mixed picture. To what extent companies are willing and can manage to integrate DFE issues into their management systems is dependent on many different factors. It appears reasonable to assume that what is an important factor for EMS or DFE individually is also important concerning their integration ${ }^{8}$. Accordingly, success factors, drivers and barriers that have been presented in literature as important for either one of the concepts have been gathered and categorised into four different levels, as shown in Figure 2. The ingredients of each level, all affecting to what extent EMS and DFE concepts are integrated and/or the outcome of such integration, are presented below. It should be observed that several of the factors listed are important on more than one level, although they are only presented within one of them. In addition, it should be stressed that the list of important factors and the accompanying argumentation are not comprehensive. This section is only intended as a general orientation to factors of importance that may be useful when analysing companies' possibilities and motives to engage in POEMS activities, as well as helpful when trying to understand why things happen or do not happen in this context.

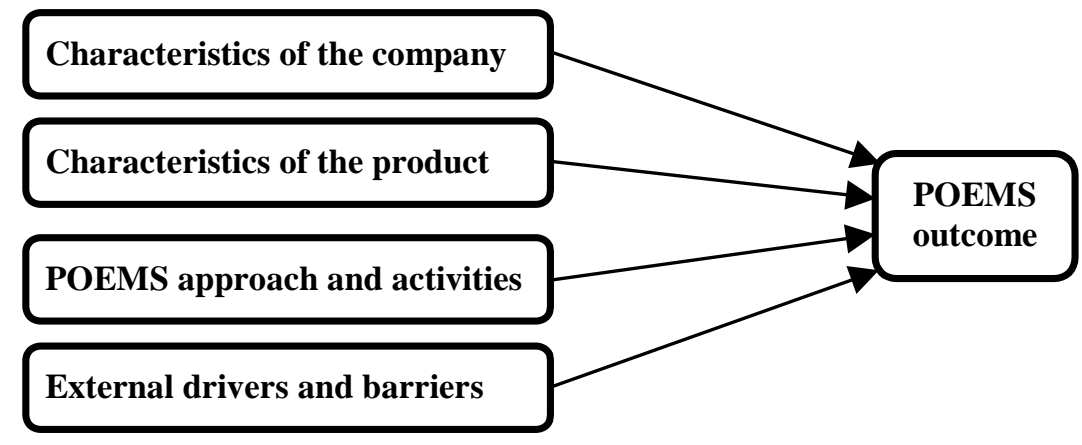

Figure 2. Four levels of important factors influencing to what extent EMS and DFE activities are integrated and/or the outcome of such integration, based on [32].

\section{Characteristics of the company}

The first level concerns the characteristics of the company. Important factors on this level include human and economical resources; company structures, systems, cultures and attitudes;

\footnotetext{
${ }^{8}$ No comprehensive literature on important drivers and barriers for POEMS has been found.
} 
motivation, knowledge and experience; and the amount and quality of available information [e.g. 29, 37]. Many researchers emphasise that especially small and medium-sized enterprises (SMEs) may encounter problems in relation to these factors when introducing an EMS or applying DFE concepts [e.g. 38, 39] or when facing environmental challenges in general [cf. 40]. SMEs have special needs for guidance adapted to their size and type of enterprise. Uncritical transfer of strategies developed for large organisations to SMEs is one general problem regarding corporate environmental strategies, tools, etc. [cf. 41, 42]. Concerning actual POEMS projects, Van Berkel et al. [12, cf. 17] point out collection and processing of environmental product information as a key bottleneck. However, POEMS can be used by SMEs and there are results showing successful POEMS projects at small firms [see 35].

Further, Johansson [43] has conducted a major literature review on important success factors concerning the integration of ecodesign into product development. On the company (management) level the following factors appears vital: provision of commitment and support; existence and clearness of environmental goals; to what extent environmental issues are addressed as business issues; and to what extent environmental issues are included when establishing a company's technological strategy.

Simonsson [44] conducted a survey among companies and experts within the area of sustainable product development and design (SPDD), which includes DFE activities. It was found that internal and external communication, technical issues and corporate culture either work as obstacles or facilitators for corporate practitioners. Other important barriers found were lack of knowledge, resources and external drivers and as enablers to SPDD; external help, market drivers and specific tools and techniques. External help asked for by the corporate practitioners most often relates to specific tools, such as software, or certain knowledge, such as consultancy and training.

\section{Characteristics of the products}

Naturally, different kinds of products have different potentials regarding environmental improvements. The characteristics of the products, which of course influence the range of available alternatives concerning production processes, influence existing opportunities for improvement. For an overview of important factors, see Figure 3, which shows how Hubka and Eder [45] have classified the product properties into four different classes. Starting at the periphery, the technical system, via the external and internal product properties, affects the product requirements used by designers. The designer determines properties such as structure, form, material content, etc.

It is important to understand that the early design phase can affect the environmental impact caused by products to a large extent. The opportunities to make changes in product design decrease with time, as the cost for these changes simultaneously increases [33]. Early decisions are important later on in the product life cycle. For example, if one wants a product facilitated for disassembly and remanufacturing, parts in the product should be easy to identify, access, separate, handle and also have high wear resistance [46, 47]. Moreover, it is advantageous to allow easy access to parts that need to be changed often, which is also a preferable property in the use phase.

Improvements may range from product improvement, product redesign, function innovation to system innovation, demanding clearly different conditions. Obviously, these conditions vary depending on the type of change. For example, the potential for improvements decreases when introducing minor modifications, such as changing one material, in comparison to 
changing the entire system within which the product is used. An example of the latter change is service selling, where focus is shifted from the traditional goods to the function that the customer wants, i.e. the key idea is to focus on the customer's need rather than on the hardware/product itself [47].

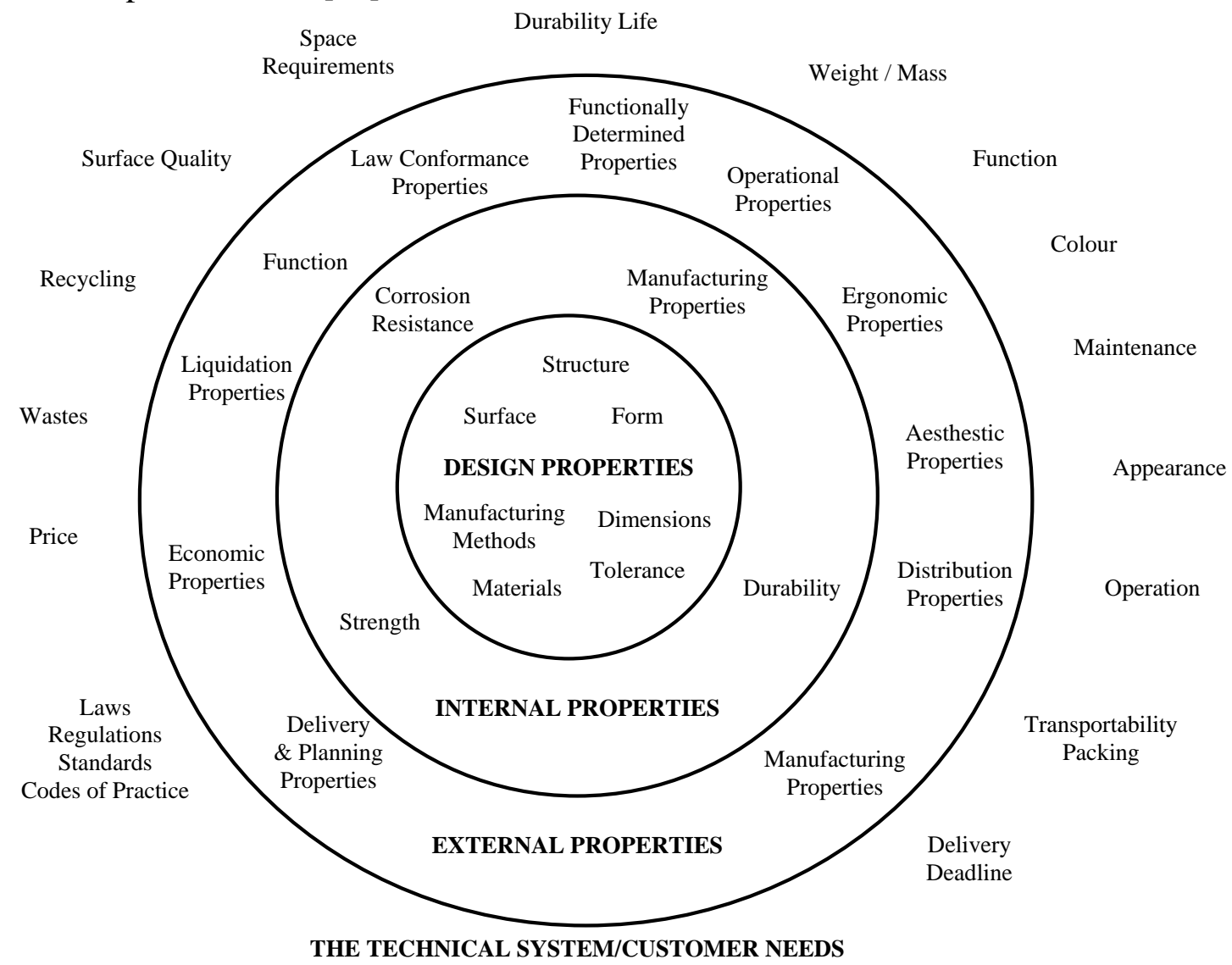

Figure 3. Relationships between classes of product properties, based on [45].

\section{POEMS approach and activities}

How the actual management system is prepared and implemented is important. The key factor is to what extent environmental criteria are integrated into the product development process and what priorities these criteria are given. This in turn is dependent on many related factors. For example, the stage at which environmental issues are considered in the product development process affects the outcome [23, 48]. Additional factors include to what extent environmental checkpoints, reviews and environmental milestone questions are introduced and if company-specific environmental design principles, rules and standards are used together with support tools [43]. It is often mentioned that suitable DFE tools are lacking [e.g. 29]. Concerning the staff, it is advisable that DFE is performed in cross-functional teams, that sufficient education and training are provided to the product development personnel and other important groups, that an environmental expert supports the development activities, and finally that examples of good design solutions are utilised (ibid.).

\section{External drivers and barriers}

The fourth level is probably the most important one, because it includes the companies' business (market) and societal environment. There are many stakeholders within the supply chain that might influence the motives and opportunities to reach environmental improvements. In addition, actors such as auditors, authorities, banks, competitors, insurance 
companies, the media, politicians and shareholders may have an important role [49]. The power structures and incentives involved certainly affect the individual firm. For a company to act, sufficient incentives are needed, often in the form of economic benefits [cf. 50]. Large corporations might have a major impact on their smaller suppliers, which has been verified by studies of the actions of, for example, Volvo and IKEA. Johansson [43] mentions a strong customer focus, training of customers in environmental issues and close supplier relationships as important characteristics of successful DFE projects. The important role of consumers should also be stressed. A market investigation showed that less than $4 \%$ of the population are willing to pay a significant premium for environmentally adapted products, though more than 70 percent of the market would choose a product/service with similar quality and price if it was environmentally adapted [51]. This stresses the importance of developing environmentally adapted products with a competitive price [cf. 23]. Of course, legislation and other instruments of control have a significant impact [23, 52]. For example, extended producer responsibility works as a driver for manufacturing companies to consider environmental issues in their product development process. It is the authors' experience that it is important that influential actors act consistently. For example, if large government-owned actors, when asking for offers from companies, include a lot of environmental requirements and emphasise environmental efforts, it is frustrating for the companies if the same actors later on always choose the lowest price, not even taking the environmental efforts into account. For companies having an EMS in place, the role of external environmental auditors is important, since they influence these companies' behaviour [10, 53]. Based on the requirements of ISO 14001 and EMAS, and their interpretations of these requirements, they decide what is needed to get an ISO 14001 certificate and/or become EMAS registered. As standardised EMS are growing in popularity the external environmental auditors are becoming one of the key players in the environmental arena [53].

\section{Concluding discussion}

This paper has shown that from a theoretical and environmental standpoint there are strong incentives to integrate DFE principles into standardised EMS. DFE-thinking could enrich EMS by contributing a life-cycle perspective, helping the organisation to identify the most important flows of materials and energy upon which to focus. Seen from a societal environmental perspective, many pollution problems related to specific sites (point sources) have been solved or clearly reduced. Instead, environmental impact caused by the consumer market, e.g. in the form of diffuse emissions, stands out as vital. Consequently, from an environmental point of view EMS covering a wider scope would be preferable and make EMS a more useful tool when striving for a sustainable development. On an organisational level, integration of EMS and DFE activities could foster better relations with stakeholders, at least those actively involved in the supply chain. It could also improve internal co-operation among members of different departments. At the same time, EMS may be useful to make DFE efforts become more permanent, i.e. lead to consistent and systematic DFE activities. Based on today's situation, it seems appropriate to picture the integration as divided into two parts. The first part concerns the integration of environmental aspects into the product development process, while the second part relates to the integration of the product development process into the management system of a company.

For companies developing POEMS, there is a common trend to develop these systems based on the PDCA-cycle, which facilitates the integration of DFE activities into such frequently used management standards as ISO 9001, ISO 14001 and EMAS. To be able to adapt the models to the individual needs of firms, POEMS models must be flexible. Hence, they normally only include an overall level of the systems, while details have to be addressed in 
accordance with the conditions for each individual company. However, some general advice for each of the steps in the PDCA-cycle could be found in the literature and have been listed in the paper. Rocha and Silvester [32] mention four different categories of activities that are included in their POEMS model, which are of a general character:

- Activities that lead to the concrete definition of environmental objectives and performance criteria for the product, as well as activities aimed for tracking progress.

- Operational activities for the improvement of products' eco-efficiency and innovation.

- Activities to ensure needed capabilities.

- Activities to establish control and routinisation.

It is far too early to draw any general conclusions on the outcomes of POEMS. However, important factors affecting this outcome can be identified on four levels, in accordance with Figure 2. In short, legislation, incentives (e.g. stakeholder interests), resources, competence, availability of supportive tools and the amount of available information can be mentioned [cf. 54]. It should be stressed that companies need sufficient drivers to engage with POEMS and the outcome greatly depends on to what extent environmental problems and challenges can be transformed into business opportunities.

Literature shows that the theoretical potential for integrating EMS and DFE concepts in some practical applications has been verified. Thus, without doubt, the marriage of the two concepts can be successful. Nevertheless, it is too early for any more general conclusions. It is not known to what degree normal EMS, i.e. systems at companies not participating in a special POEMS project, include products. The literature shows a mixed picture. Some results indicate that normal EMS lead to increased DFE activities, while others show that the link between normal EMS and DFE concepts is weak. Very little is written on how POEMS affect firms' environmental performance.

It appears to be likely that the environmental burden from products' life cycles would be reduced if the product connection was strengthened in existing standardised EMS, which consequently would increase the environmental efficiency of EMS. Accordingly, efforts to adjust the standard ISO 14001 and the systems for its application would be advantageous from an environmental point of view. External environmental auditors and environmental consultants have important roles in this arena, since they could function both as a driver and a barrier for the integration of standardised EMS and DFE concepts [10, c.f. 9, 53]. However, the paper has pointed out many important factors apart from EMS that must be adjusted as well to reach improvements in environmental performance.

\section{Acknowledgements}

This research was sponsored by the Swedish Association of Graduate Engineers and The Programme for Production Engineering Education and Research.

\section{References}

[1] ISO (International Organization for Standardization). Environmental Management Systems - Specification with Guidance for Use (ISO 14001:1996). Stockholm: Swedish Standards Institution, 1996.

[2] European Commission. Official Journal of the European Communities. 1993: L 168, vol. 1, no. 1836/93, July 10.

[3] ISO World. The Number of ISO14001/EMAS Certification/Registration in the World. 
December 2002. Internet site: http://www.ecology.or.jp/isoworld/english/analy14k.htm. ISO World. Access: April 16th, 2003.

[4] Andrews RNL, Darnall N, Rigling Gallagher D, Terill Keiner S, Feldman E, Mitchell M, Amaral D and Jacoby J. Environmental Management Systems: History, Theory, and Implementation Research. In: Coglianese $\mathrm{C}$ and Nash J, editors. Regulation from the Inside: Can Environmental Management Systems Achieve Policy Goals? Washington, DC: Resources for the Future Press, 2001.

[5] Ammenberg, J. How Do Standardised Environmental Management Systems Affect Environmental Performance and Business? Licentiate thesis no. 907. ISBN 91-7373-124-2. Environmental technique and management. Linköping University, Sweden, 2001.

[6] Ayres RU. Industrial Metabolism: Theory and Policy. In: Ayres RU and Simonis UE, editors. Industrial Metabolism - Restructuring for Sustainable Development. Tokyo: United Nations University, 1994:3-20.

[7] Berkhout, F. Aggregate Resource Efficiency. Are Radical Improvements Impossible? In: Vellinga P, Berkhout F and Gupta J., editors. Managing a Material World. Perspectives in Industrial Ecology. Kluwer Academic Publishers, 1998: 165-89.

[8] Graedel TE and Allenby BR. Industrial Ecology. London: Englewood Cliffs, Prentice Hall, 1995. ISBN 0-13-125238-0.

[9] Karlsson M. Green Concurrent Engineering. A Model for DFE Management Programs. Doctoral Dissertation, the International Institute for Industrial Environmental Economics, Lund University, Sweden, September, 2001.

[10] Ammenberg J and Sundin E. Products in Environmental Management Systems - the Role of Auditors. Submitted to Journal of Cleaner Production, 2003.

[11] VROM. Letter of the Minister of Housing, Spatial Planning and the Environment to the Lower House on November 15, 1995. The Hague, The Netherlands, Ministry of Housing, Spatial Planning and the Environment, 1995.

[12] van Berkel R, van Kampen M and Kortman J. Opportunities and Constraints for ProductOriented Environmental Management Systems (P-EMS). Journal of Cleaner Production, 1999;7:447-55.

[13] Rocha C and Brezet H. Product-Oriented Environmental Management Systems: A Case Study. The Journal of Sustainable Product Design, July 1999: 30-42.

[14] Sinding K. Environmental Management Beyond the Boundaries of the Firm: Definitions and Constraints. Business Strategy and the Environment, 2000;9:79-91.

[15] Ammenberg J and Hjelm O. The Connection Between Environmental Management Systems and Continual Environmental Performance Improvements. Corporate Environmental Strategy, 2002;9(2):183-92.

[16] Cramer J. Towards Innovative, More Eco-Efficient Product Design Strategies. The Journal of Sustainable Product Design, 1997;1:7-16.

[17] Klinkers L, van der Kooy W and Wijnen H. Product-oriented Environmental Management Provides New Opportunities and Directions for Speeding Up Environmental Performance. Greener Management International, summer 1999: 91-108.

[18] Ries G, Winkler R, and Züst R. Barriers for a Successful Integration of Environmental Aspects in Product Design. Proceedings of "EcoDesign '99”. First international symposium on environmental conscious design and inverse manufacturing, 1999: February 
1-3, Tokyo, Japan: 527-32.

[19] Hjelm O, Lundgren J and Idegren L. Miljöledd Produktutveckling. Ett Projekt i Skärningspunkten mellan Miljöledning och Miljöanpassad Produktutveckling, Slutrapport till NUTEK, Linköping University and IVF, 2001 (in Swedish).

[20] Charter M and Belmane I. Integrated Product Policy (IPP) and Eco-Product Development (EPD). The Journal of Sustainable Product Design, July 1999:17-29.

[21] Simon M, Evans S, McAloone T, Sweatman A, Bharma T and Poole S. Ecodesign Navigator, Manchester Metropolitan University, Cranfield University and EPSRC, UK, ISBN 1-871315-74-3.

[22] McAloone TC. Industrial Application of Environmentally Conscious Design, London : Professional Engineering Publishing Limited and Bury St. Edmunds United, 2000. ISBN 1-86058-239-7.

[23] Bäckmar J. Strategies for Sustainable Product Development - Managing the Environmental Challenge, Licentiate thesis, TRITA-MMK 2000:10, Integrated Product Development, Department of Machine Design, Royal Institute of Technology, Stockholm, Sweden, 2000, ISSN 1400-1179.

[24] Lenox M and Ehrenfeld J. DfE: A New Framework for Strategic Decisions. Total Environmental Quality Journal, June 1995.

[25] Brezet H and Rocha C. Towards a Model for Product-Oriented Environmental Management Systems. In: Charter M and Tischner U, editors. Sustainable Solutions. Sheffield: Greenleaf Publishing, 2001:243-61.

[26] BATE (Business and the environment). Lucent Technologies Applies ISO 14001 to design for environment functions. ISO 14001 Update 6.2, February, 2000.

[27] Grüner C, Dannheim F and Birkhofer H. Integration of EMS and DFE. Current practise and future trends. Proceedings from the $6^{\text {th }}$ International Seminar on Life Cycle Engineering. Kingston, Ontario, 1999:131-40.

[28] Deming WE. Out of the Crisis. MA: MIT, Cambridge, 1986.

[29] Brezet H, Houtzager B, Overbeeke R, Rocha C and Silvester S. Evaluation of 55 POEM Subsidy Projects. Product Oriented Environmental Management. Delft Technical University, Internal report, August 2000.

[30] Jarvinen J, Perklen E, Kaila-Stenberg S, Hyvarinen E, Hyytianinen S and Tornqvist E. The PDCA-cycle in Implementing Design for the Environment in an R\&D Unit of Nokia Telecommunications. Proceedings from the IEEE 1998 International Symposium on Electronics and the Environment. (Dillon, P. and Ufford, D., editors) IEEE. Piscataway, NJ, 1998:237-42.

[31] Cramer J and Alders G. The Design of a Product Stewardship Management System Within Akzo Nobel. Eco-Management and Auditing, 1999;6: 135-39.

[32] Rocha C and Silvester S. Product-Oriented Environmental Management Systems (POEMS). From Theory to Practice - Experiences in Europe. Extended abstract published at the 1st Life Cycle Management Conference in Copenhagen, 2001.

[33] Bergman B and Klefsjö B. Quality from Consumer Needs to Customer Satisfaction, Lund : Studentlitteratur, 1994. ISBN 91-44-46331-6.

[34] Ulrich KT and Eppinger SB. Product Design and Development, $2^{\text {nd }}$ Edition, Boston: 
McGraw-Hill, 2000, ISBN 0-07-229647-X.

[35] van Hemel C. Ecodesign Empirically Explored: Design for Environment In Dutch Small and Medium-Sized Enterprises. PhD Thesis: Design for Sustainability Research Programme, Publication no 1: Delft, The Netherlands, 1998.

[36] Bunyagidj C and Greason D. Promoting Cleaner Production in Thailand: Integrating Cleaner Production into ISO 14001 Environmental Management Systems. Industry and Environment, 1996;19:44-47.

[37] Tinsley S. EMS Models for Business Strategy Development. Business Strategy and the Environment, 2002;11:376-90.

[38] Hillary R. Evaluation of Study Reports on the Barriers, Opportunities and Drivers for Small and Medium-Sized Enterprises in the Adoption of Environmental Management Systems. London: Department of Trade and Industry, Environmental Directorate, 1999.

[39] van Hemel C and Cramer J. Barriers and Stimuli for Ecodesign in SMEs. Journal of Cleaner Production, 2002;10(5):439-53.

[40] Tilley F. Small-Firm Environmental Strategy. The UK Experience. Greener Management International, 1999;25:1-14.

[41] Dandridge TC. Children Are Not “Little Grown-ups”: Small Business Needs Its Own Organizational Theory. Journal of Small Business Management, April 1979;17(2):53-57.

[42] Welsh JA and White JF. A Small Business Is Not a Little Big Business. Harvard Business Review, Jul/Aug 1981;59:18-32.

[43] Johansson G. Success Factors for Integration of Ecodesign in Product Development - A Review of State-of-the-art, Environmental Management and Health, 2002;13(1): 98-107.

[44] Simonsson A. Application of Sustainable Product Development and Design - a Pilot Study of the State of the Art, Barriers and Enablers, Master's thesis, LiTH-IFM-Ex-1072, Department of Physics and Measurement Technology, Linköping University, Sweden, 2002.

[45] Hubka V and Eder WE. Theory of Technical Systems - A Total Concept Theory for Engineering Design, $2^{\text {nd }}$ Edition. Berlin: Springer-Verlag, 1988, ISBN 3-540-17451-6.

[46] Johansson G. Design for Disassembly - A Framework, Linköping Studies in Science and Technology, thesis no. 651, Department of Mechanical Engineering, Linköping University, Sweden, 1997, ISBN 91-7219-101-5.

[47] Sundin E. Design for Remanufacturing from a Remanufacturing Process Perspective, Linköping Studies in Science and Technology, Licentiate Thesis No. 944, LiU-TEK-LIC2002-17, Department of Mechanical Engineering, Linköping University, Sweden, 2002, ISBN 91-7373-336-9.

[48] Ullman DG. The Mechanical Design Process, $2^{\text {nd }}$ Edition, Singapore: McGraw-Hill, 1997, ISBN 0-07-115576-7.

[49] Hibbit C and Kamp-Roelands N. Europe's (Mild) Greening of Corporate Environmental Management. Corporate Environmental Strategy, 2002;9(1):1-11.

[50] Porter M. Competitive Advantage: Creating and Sustaining Superior Performance. London, New York: Free Press, 1985.

[51] Cohen-Rosenthal E. Eco-Industrial Development: New Frontiers for Organizational Success, Proceedings of $5^{\text {th }}$ International Conference on Environmentally Conscious 
Design and Manufacturing, 1998. Available for downloading at: http://www.cfe.cornell.edu/WEI/eipnewfrontiers.htm

[52] VINNOVA. Drivers of Environmental Innovation. Report from VINNOVA, The Swedish Agency for Innovation Systems, Stockholm: VF 2001:1.

[53] Ammenberg J, Wik G and Hjelm O. Auditing External Environmental Auditors Investigating How ISO 14001 is Interpreted and Applied in Reality. Eco-Management and Auditing, 2001;8:183-92.

[54] de Bakker F. Product-Oriented Environmental Management. A Study of CapabilityBuilding, Stakeholder Orientation and Continuous Improvement Regarding Product's Environmental Characteristics In Firms. Dissertation published by Twente University Press, 2001, ISBN 903651567x. 